\title{
FENOMENA MIGRASI SIRKULER DI KOTA MATARAM
}

\section{NI PUTU FEBBY SUNDARI ${ }^{1)}$, PUTU KARISMAWAN ${ }^{2)}$, EMY SALMAH ${ }^{3)}$}

\author{
${ }^{1)}$ Alumni. ${ }^{2,3)}$ Dosen Fakultas Ekonomi dan Bisnis Universitas Mataram
}

\author{
e-mail : putukarismawan@gmail.com
}

\begin{abstract}
ABSTRAK
Secara teoritis, salah satu faktor yang menentukasn pertumbuhan suatu kota adalah ketersediaan tenaga kerja. Umumnya ketersediaan tenaga kerja di suatu kota sebagaian bersumber dari luar kota atau daerah penyangga (Periphery). Kemajuan sarana prasarana transportasi menjadi faktor yang menetukan mobilitas tenaga kerja dari daerah penyangga ke perkotaan. Ada dua pilihan bagi tenaga kerja yang berasal dari luar kota yaitu menetap di suatu kota ataukah tetap berdomisil di daerah asala( migrasi sirkuler).

Penelitian ini menganalisis faktor-faktor yang mempengaruhi minat tenaga kerja luar kota memilih untuk melakukan migrasi sirkuler. Secra lebih spesifik apakah faktor-faktor pendapatan, lama bekerja, umur, jarak, tingkat pendidikan, dan status perkawinan berpengaruh terhadap minat tenaga kerja untuk melakukan migrasi sirkuler. Alat analisis yang digunakan adalah analisis regresi logistik yaitu Binary Regression Logistic. Sampel tenaga kerja sebanyak 80 sampel responden.

Hasil penelitian menunjukkan bahwa variabel pendapatan, lama bekerja, umur, jarak, tingkat pendidikan dan status perkawinan berpengaruh secara simultan dan signifikan terhadap minat pekerja melakukan migrasi sirkuler ke Kota Mataram. Faktor - faktor yang secara parsial berpengaruh signifkan terhadap minat pekerja melakukan migrasi sirkuler ke Kota Mataram dengan nilai signifikansi dengan taraf alpha 5\% adalah variabel pendapatan, lama bekerja, jarak dan tingkat pendidikan. Sedangkan variabel umur dan status perkawinan tidak berpengaruh signifikan terhadap minat pekerja melakukan migrasi sirkuler ke Kota Mataram.
\end{abstract}

Kata kunci : Pekerja, migrasi sirkuler

\section{ABSTRACT}

Theoretically, development of the city depends on labor resources. Generally, labor resources of the city come from periphery area. Developed infrastructure is a factor that mobilized labor resources from periphery to the city. There are two alternatives to the workers who come from periphery area; first they can stay in the city by renting apartment or the second as commuter. Many of the workers choose as commuter, so it is quite interesting to know what factors influence workers make choice as commuter. It is more specific whether factors such as income, length of work, age, distance, education level, and marital status influence the interest of workers to conduct circular migration. The analytical tool used is logistic regression analysis, Binary Regression Logistic.

This research is a descriptive study that uses quantitative analysis using 1 dependent variable, namely interest in migration and six independent variables, namely income, length of working, age, distance, education level, and marital status. To achieve these objectives in this research logistic regression analysis was used, namely Binary Regression using primary data as many as 80 respondents.

The results show that above variables; income, length of working, age, distance, level of education and marital status simultaneously and significantly influence on interest of workers in doing circulation migration to the Mataram City. Factors that partially influence significantly on the interest of workers doing migration to the Mataram City with a significance value with an alpha level of 5\% are income, length of working, distance and level of education. While the age variable and marital status is not significant in effect.

Keywords : Workers, circular migration 


\section{PENDAHULUAN}

Fenomena migrasi umum terjadi dibeberapa negara berkembang, termasuk diberbagai daerah di Indonesia, terutama dalam konteks dimana banyak tenaga kerja yang berasal dari daerah pedesaan mengalir ke daerah perkotaan. Proses migrasi yang berlangsung dalam suatu negara (internal migration) dianggap sebagai proses alamiah yang akan menyalurkan surplus tenaga kerja di daerah - daerah ke sektor industri modern di kota - kota yang memiliki daya serap lebih tinggi. Walaupun pada kenyataannya arus perpindahan tenaga kerja dari daerah pedesaan ke perkotaan tersebut, telah melampaui tingkat penciptaan lapangan kerja sehingga migrasi yang terjadi jauh melampaui daya serap sektor industri dan jasa di daerah perkotaan (Todaro).

Pada hakekatnya mobilitas penduduk (migrasi) merupakan suatu gambaran perbedaan pertumbuhan dan ketidakmerataan fasilitas pembangunan antara satu daerah dengan daerah lainnya. Fenomena yang kemudian muncul adalah munculnya tenaga kerja dari daerah yang mempunyai fasilitas pembangunan minim akan bergerak menuju ke daerah yang mempunyai fasilitas pembangunan lebih baik, yaitu antara wilayah pedesaan dengan wilayah perkotaan.

Kota memegang peranan penting di dalam perkembangan masyarakat. Kota menjadi semacam wadah kegiatan manusia, tidak dapat dihindari bahwa kota berubah setiap waktu baik dari segi ukuran besar, struktur serta pentingnya. Dengan sendirinya, perubahan ini mengakibatkan ketidakseimbangan dimana mana.

Dalam banyak teori migrasi dijelaskan bahwa motivasi utama penduduk untuk berpindah adalah karena adanya motif ekonomi, motif ini berkembang disebabkan adanya ketimpangan ekonomi antar berbagai daerah. Adanya kesempatan untuk memperoleh pekerjaan yang lebih baik atau pendapatan yang lebih besar. Tingkat gaji atau upah yang diperoleh di desa belum dapat menjamin kesejahteraan para migran dan keluarganya. Perbedaan tingkat upah antara desa dengan kota tersebut mendorong penduduk bermigrasi ke kota untuk mencukupi kebutuhan yang semakin beraneka ragam. Penduduk baru akan memutuskan untuk melakukan migrasi jika penghasilan bersih di kota melebihi penghasilan bersih yang tersedia di desa (Todaro, 2000).

Mantra (2015) menjelaskan bahwa seseorang yang telah lama tinggal di daerah tujuan cenderung memilih tempat tinggal yang dekat dengan daerah mereka bekerja. Pelaku mobilitas sirkuler yang telah lama bekerja di daerah tujuan umumnya mampu menjalin hubungan kekerabatan baru dengan masyarakat atau lingkungan di daerah tujuannya dan berniat untuk menetap.

Selain itu, usia juga berpengaruh terhadap minat migrasi penduduk, dimana pada usia 15 - 64 tahun termasuk usia potensial sebagai pekerja. Sedangkan penduduk yang berumur lebih tua biasanya berniat untuk menetap atau menolak untuk melakukan perpindahan. (De Jong dalam Dina, 2008).

Menurut E.G Ravenstein, jarak merupakan pertimbangan yang dominan dan utama untuk menentukan minat bermigrasi khususnya yang migrasi sirkuler yang bersifat ulang - alik karena mempertimbangkan efisiensi biaya dan efektivitas waktu yang tersedia. Sesungguhnya jarak seperti magnet bila semakin dekat maka akanmembuat minat migrasi akan semakin kuat.Selain itu, terdapat hubungan yang jelas antara tingkatberpendidikan lebih tinggi cenderung lebih banyak melakukan migrasidaripada yang pendidikannya lebih rendahpendidikan yang dicapai dan keinginan untuk bermigrasi (Arsyad, 2009).

Status perkawinan juga mempengaruhi keputusan seseorang untukbermigrasi. Seseorang yang terikat pernikahan maka beban hidup yang ditanggung akan bertambah, terlebih bagi seorang laki - laki. Oleh karena itu dia memutuskan untuk mencari pekerjaan di kota demi kesejahteraan keluarganya. Bagi penduduk yang tidak terikat pernikahan, keputusan bermigrasi ke kota merupakan kesempatan untuk memperoleh pengetahuandan pengalaman yang tidak bisa didapatkan di desa. Faktor - faktor yang mempengaruhi keputusan untuk melakukan migrasi sangatlah beragam dan kompleks, karena migrasi itu adalah proses yang menyangkut individual - individual dengan karakteristik ekonomi, sosial, pendidikan dan demografi.

Penduduk dalam melakukan mobilitas lebih tertarik melakukan perpindahan jarak dekat atau melakukan migrasi non permanen. Hal ini dapat terjadi karena adanya rasa keterikatan penduduk terhadap keluarga, teman, maupun kampung halaman yang ditinggalkan. Menurut Mantra dalam Atik Nuraini (2006), mobilitas penduduk non permanen disebabkan karena adanya perbedaan kekuatan antara kekuatan sentrifugal (faktor pendorong meninggalkan daerah asal) dan kekuatan setripetal (faktor penarik untuk tetap tinggal di daerah tujuan). Adanya kesulitan biaya hidup untuk tinggal di kota, lahan di daerah asal, jenis pekerjaan di daerah asal menyebabkan penduduk jenis pekerjaan di daerah asal menyebabkan penduduk yang melakukan mobilitas cenderung melakukan migrasi non permanen. Banyaknya perantau atau migrasi sirkuler khususnya di Kota Mataram dapat menimbulkan dampak positif dan negatif baik bagi daerah asal 
maupun daerah tujuan migrasi. Arus migrasi yang dilakukan sebagian besar penduduk desa ke kota menarik untuk diamati dan dikaji mengingat fenomena tersebut hanya terjadi pada negara - negara berkembang termasuk Indonesia yang masih cukup jarang untuk diteliti.

\section{METODE PENELITIAN}

\section{Lokasi Penelitian dan Waktu Penelitian}

Penelitian ini dilaksanakan di Kota Mataram, dengan pertimbangan bahwa Kota Mataram merupakan wilayah pusat kegiatan ekonomi masyarakat Nusa Tenggara Barat yang memiliki struktur ekonomi yang cenderung berbasis sektor - sektor modern yang dapat menyerap banyak tenaga kerja, sehingga cukup banyak masyarakat yang melakukan migrasi secara sirkuler ke wilayah tersebut dengan tujuan untuk bekerja. Penelitian ini dilakukan pada Tahun 2019.

\section{Populasi dan Sampel Penelitian}

\section{Populasi}

Populasi dalam penelitian ini adalah seluruh migran sirkuler yang bersifat ulang alik / mondok, baik yang berjenis kelamin laki - laki maupun perempuan yang memiliki pekerjaan dan bekerja di Kota Mataram, dimana masyarakat tersebut berasal dari luar Kota Mataram menetap di Kota Mataram dan memiliki KTP (Kartu Tanda Penduduk) bukan Kota Mataram, namun bekerja di Kota Mataram. Dalam penelitian ini jumlah populasi migran sirkuler tersebut belum dapat diketahui secara pasti, sehingga populasi pada penelitian ini merupakan populasi tak terhingga.

\section{Sampel}

Dikarenakan populasi pada penelitian ini bersifat tidak terhingga (tidak diketahui jumlahnya) sehingga tidak dapat dihitung menggunakan rumus - rumus penentuan ukuran sampel. Besaran sampel yang diambil dalam penelitian ini sebanyak 80 responden di Kota Mataram. Besaran sampel yang diambil, dipertimbangkan berdasarkan adanya keterbatasan biaya, waktu, dan tenaga peneliti serta berpedoman pada pernyataan Roscoe dalam Uma Sekaran (2017) yang menyatakan bahwa ukuran sampel lebih dari 30 dan kurang dari 500 adalah tepat untuk kebanyakan peneliti dan juga dalam penelitian multivariate, ukuran sampel sebaiknya 10x lebih besar dari jumlah variabel dalam penelitian. Berpedoman pada pernyaataan tersebut, dengan jumlah sampel sebesar 80 orang pada penelitian ini, maka ukuran sampel yang sudah ditentukan tersebut dianggap sudah dapat mewakili populasi pada penelitian.

Metode yang digunakan dalam menentukan sampel pada penelitian ini adalah teknik Snowball Sampling. Snowball Sampling merupakan teknik pengumpulan sampel yang mula - mula jumlahnya kecil, kemudian membesar. Ibarat bola salju yang menggelinding semakin besar. Dalam penentuan sampel, pertama - tama dipilih satu atau dua orang, tetapi karena dengan dua orang ini belum merasa lengkap terhadap data yang diberikan, maka peneliti mencari orang lain yang dipandang lebih tahu dan dapat melengkapi data yang diberikan oleh dua orang sebelumnya. Begitu seterusnya, sehingga jumlah sampel semakin banyak (Sujarweni, 2018).

\section{Variabel dan Definisi Operasional Variabel}

Variabel yang digunakan dalam penelitian ini dapat diklasifikasikan sebagai berikut :

Variabel terpengaruh atau variabel terikat (variabel dependen) yaitu Minat Migrasi ( $\mathrm{Y}$ ) dan Variabel pengaruh atau variabel bebas (variabel independen) : Pendapatan $\left(\mathrm{X}_{1}\right)$, Lama Bekerja $\left(\mathrm{X}_{2}\right)$, Umur $\left(\mathrm{X}_{3}\right)$, Jarak $\left(\mathrm{X}_{4}\right)$, Tingkat Pendidikan $\left(\mathrm{X}_{5}\right)$, Status perkawinan $\left(\mathrm{X}_{6}\right)$

Definisi Operasional Variabel :

a. Minat Migrasi (Y)

Minat migrasi dalam penelitian ini adalah keinginan atau niatan seseorang untuk melakukan mobilitas atau perpindahan dari suatu wilayah ke wilayah lain (kabupaten/kota) dalam jangka waktu kurang atau lebih dari enam bulan, jika kurang dari enam bulan maka bentuk migrasi tersebut non permanen (sirkuler) sedangkan jika lebih dari enam bulan merupakan migrasi permanen (menetap). Dalam penelitian ini 
variabel terikat merupakan variabel dummy dengan 2 kategori, yaitu 0 untuk responden berniat untuk menetap di daerah tujuan (Kota Mataram), sedangkan 1 untuk responden berniat tetap melakukan migrasi sirkuler.

b. Pendapatan $\left(\mathrm{X}_{1}\right)$

Pendapatan yang dimaksud dalam penelitian ini adalah upah atau gaji yang diperoleh oleh responden di tempat mereka bekerja di daerah tujuan (Kota Mataram) dalam kurun waktu perbulan, yang diukur menggunakan data ordinal sebagai berikut : 1). $\leq$ Rp 1.499.999, 2) Rp 1.500.000 - Rp 2.999.999, 3). Rp 3.000.000 - Rp 4.499.000, dan 4). $\geq$ Rp 4.500.000.

c. Lama bekerja $\left(\mathrm{X}_{2}\right)$

Lama responden sudah bekerja di daerah tujuan (Kota Mataram) yang diukur dengan satuan tahun.

d. $\operatorname{Umur}\left(\mathrm{X}_{3}\right)$

Umur responden berdasarkan tanggal lahir sampai dengan genap tahun yang terlewati. Usia merupakan variabel continous yang diukur melalui satuan tahun.

e. Jarak $\left(\mathrm{X}_{4}\right)$

Jarak merupakan jarak yang ditempuh responden dari daerah asal ke daerah tujuan (Kota Mataram) tempat mereka bekerja yang diukur dengan satuan kilometer.

f. Tingkat pendidikan $\left(\mathrm{X}_{5}\right)$

Tingkat pendidikan merupakan jenjang pendidikan terakhir yang dicapai oleh responden yang diukur dengan data ordinal, diman $0=$ tidak bersekolah, $1=$ SD, $2=$ SLTP (SMP/MTS), $3=$ SLTA (SMA/SMK/MA), 4 = diploma (D1/D2/D3), dan $5=$ sarjana (S1/S2/S3).

g. Status perkawinan $\left(\mathrm{X}_{6}\right)$

Status perkawinan adalah status responden yang disandang responden. Status perkawinan yang diukur dengan variabel dummy, dimana $0=$ responden belum menikah/masih lajang, sedangkan $1=$ sudah menikah, duda/janda.

\section{Alat Analisis}

\section{Analisis Logistik}

Data penelitian dikumpulkan dan diolah, selanjutunya dianalisis menggunakan alat analisis statistik atau dilakukan pengujian hipotesis. Pengujian hipotesis dilakukan secara multivariate dengan menggunakan regresi logistik (Logistic Regression Model), dimana variabel terikatnya berbentuk non parametris atau kategoris. Tujuan dari uji diskriminan ini adalah untuk mengidentifikasi variabel - variabel yang mampu membedakan antara kedua kelompok yang berbeda.

Ketegorisasi variabel terikat (variabel dependen) dapat dijelaskan sebagai berikut :

1. Angka 1 untuk responden yang berniat tetap melakukan migrasi sirkuler.

2. Angka 0 untuk responden yang berniat untuk menetap di daerah tujuan.

Penggunaan model regresi logistik dianggap sebagai alat yang paling tepat untuk menganalisis data didalam penelitian ini dikarenakan variabel dependen bersifat dikotomi atau multinominal yaitu lebih dari satu atribut (Hossain, 2001).Regresi logistik dengan dua pilihan sering disebut Binary Logistic Regression karena model yang dihasilkan bersifat nonlinier, persamaan yang digunakan untuk mendeskripsikan hasil sedikit lebih komplek dibandingkan regresi berganda.

Kelebihan metode regresi logistik yaitu lebih fleksibel dibandingkan dengan metode lainnya (Mudrajat Kuncoro dalam Atik, 2006) :

- Regresi logistik tidak memiliki asumsi normalitas atas variabel bebas yang digunakan dalam model, artinya bahwa variabel penjelas tidak harus memiliki distribusi normal linier maupun memiliki varian yang sama dalam setiap grup.

- Variabel bebas dalam regresi logistik dapat campuran dari variabel kontinyu, diskrit, dan dikotomis.

- Regresi logistik bermanfaat digunakan apabila distribusi variabel terikat diharapkan non linier satu atau lebih variabel bebas.

Perumusan model secara lengkap dapat dinotasikan dalam persamaan matematis :

$$
\hat{\mathbf{Y}}=\boldsymbol{\beta}_{0}+\boldsymbol{\beta}_{1} \mathbf{x}_{1}+\boldsymbol{\beta}_{2} \mathbf{x}_{2}+\beta_{3} \mathbf{x}_{3}+\boldsymbol{\beta}_{4} \mathbf{x}_{4}+\beta_{5} \mathbf{x}_{5}+\boldsymbol{\beta}_{6} \mathbf{x}_{6}+\alpha
$$

\section{Keterangan :}

$\hat{\mathrm{Y}}$ :Minat Migrasi, 1 untuk responden yang berniat migrasi secara tidak menetap dan 0 untuk responden yang berniat migrasi secara menetap. 
$\mathrm{X}_{1}$ : Pendapatan

$\mathrm{X}_{2}$ : Lama bekerja

$\mathrm{X}_{3}:$ Umur

$\mathrm{X}_{4}:$ Jarak

$\mathrm{X}_{5}$ :Tingkat pendidikan

$\mathrm{X}_{6}:$ Status perkawinan

$\beta_{0}:$ Intersep

$\beta_{1,2,3,4,56}$ : Koefisien regresi

$\alpha:$ Kesalahan pengganggu (error term)

Dalam menentukan justifikasi signifikansi statistik bagi masing - masing variabel yang diuji adalah dengan berdasarkan pada nilai probabilitas $\alpha=0,05(5 \%)$, maka variabel independen yang diamati berpengaruh secara signifikan terhadap variabel dependennya.

\section{HASIL DAN PEMBAHASAN}

\section{Analisis Logistik}

Hasil analisis regresi logit (binary logistic regression), dimana variabel terikat pada penelitian ini berupa data nominal dalam bentuk dummy, dengan 2 kategori yaitu 0 untuk responden yang berniat menetap di daerah tujuan dan 1 untuk responden yang berniat tetap melakukan migrasi sirkuler, sebagai berikut:

$$
\hat{Y}=6,916-1,519 X 1-0,296 X 2+0,163 X 3-0,091 X 4-0,989 X 5-1,051 X 6+e
$$

\section{Uji Hipotesis}

\section{Wald Test (Uji Parsial)}

Uji wald test digunakan untuk pengujian individu (parsial) yang menunjukkan apakah variabel bebas berpengaruh signifikan terhadap variabel terikat. Variabel bebas berpengaruh signifikan jika nilai signifikan variabel bebas lebih kecil dibandingkan standar eror 0,05 , maka $\mathrm{H}_{\mathrm{a}}$ diterima dan $\mathrm{H}_{0}$ ditolak

Tabel 1. Wald Test

\begin{tabular}{|l|c|c|c|c|}
\hline \multicolumn{1}{|c|}{ Variabel } & $\beta$ & Wald & Sig. & $\operatorname{Exp}(\beta)$ \\
\hline Pendapatan & $-1,519$ & 6,734 & 0,009 & 0,219 \\
\hline Lama Bekerja & $-0,296$ & 5,187 & 0,023 & 0,744 \\
\hline Umur & 0,163 & 2,405 & 0,121 & 1,177 \\
\hline Jarak & $-0,091$ & 7,739 & 0,005 & 0,913 \\
\hline Tingkat Pendidikan & $-0,989$ & 5,283 & 0,022 & 0,372 \\
\hline Status Perkawinan & $-1,051$ & 1,263 & 0,216 & 0,349 \\
\hline
\end{tabular}

Sumber : Data Primer, Diolah 2019 (SPSS 21)

Dari tabel di atas terlihat bahwa variabel pendapatan dengan nilai signifikan sebesar 0,009 , variabel lama bekerja dengan nilai signifikan sebesar 0,023, variabel jarak dengan nilai signifikan sebesar 0,005, dan variabel tingkat pendidikan dengan nilai signifikan sebesar 0,022 karena nilai signifikan masing - masing variabel tersebut lebih kecil dari standar eror 0,05 , sehingga $\mathrm{H}_{\mathrm{a}}$ diterima dan $\mathrm{H}_{0}$ ditolak maka empat variabel bebas tersebut berpengaruh signifikan terhadap minat pekerja melakukan migrasi sirkuler ke Kota Mataram.

Sedangkan variabel bebas yang tidak berpengaruh secara signifikan terhadap minat migrasi sirkuler pekerja adalah variabel umur dengan nilai signifikan 0,121 dan status perkawinan dengan nilai signifikan 0,216 karena nilai signifikan masing - masing variabel tersebut lebih besar dari standar eror 0,05, maka $_{\mathrm{a}}$ di tolak dan $\mathrm{H}_{0}$ diterima. 
Tabel 2. Omnibus Test

\begin{tabular}{|c|c|}
\hline Chi - Square & Sig. \\
\hline 51,687 & 51,687 \\
\hline
\end{tabular}

Sumber : Data Primer, Diolah 2019 (SPSS 21)

Dari tabel diatas terlihat bahwa nilai signifikan chi-square sebesar 0,000 lebih kecil dari standar eror 0,05, maka $\mathrm{H}_{\mathrm{a}}$ diterima dan $\mathrm{H}_{0}$ ditolak yang artinya bahwa variabel pendapatan, lama bekerja, umur, jarak, tingkat pendidikan, dan status perkawinan secara serentak mempengaruhi minat pekerja untuk melakukan migrasi sirkuler ke Kota Mataram.

\section{Nagelkerke R Square (Uji Koefisien Determinasi)}

Ukuran $\mathrm{R}^{2}$ pada metode logistik diketahui dari nilai Nagelkerke $R$ Square yang didasarkan pada teknik estimasi likelihood dengan nilai yang bervariasi dari nol (0) sampai satu (1).

\begin{tabular}{|} 
Tabel 3. Nagelkerke R Square \\
\begin{tabular}{|c|c|c|}
\hline$-2 \operatorname{loglikelihood}$ & $\begin{array}{c}\text { Cox \& Snell R } \\
\text { Square }\end{array}$ & $\begin{array}{c}\text { Nagelkerke R } \\
\text { Square }\end{array}$ \\
\hline $58,416^{\mathrm{a}}$ & 0,476 & 0,637 \\
\hline Sumber : Data Primer, Diolah 2019 (SPSS 21)
\end{tabular}
\end{tabular}

Dari hasil regresi diatas terlihat bahwa nilai nagelkerke $r$ square sebesar 0,637 atau $63,7 \%$ yang artinya bahwa variabel pendapatan, lama bekerja, umur, jarak, tingkat pendidikan dan status perkawinan mempengaruhi minat pekerja untuk melakukan migrasi sirkuler sebesar $63,7 \%$, sedangkan sisanya sebesar $36,3 \%$ dipengaruhi oleh variabel lain yang tidak masuk kedalam model regresi, variabel lain tersebut seperti kepemilikan lahan di daerah asal, status pekerjaan, beban tanggungan pekerja.

\section{Interpretasi Hasil}

Berdasarkan tabel dan model binary logistic dapat dijelaskan bahwa :

1. Variabel Pendapatan Pekerja Di Daerah Tujuan

Nilai koefisien $(\beta)$ sebesar $-1,519$ dan nilai signifikan 0,009 yang artinya bahwa pendapatan pekerja berpengaruh negatif dan signifikan terhadap minat pekerja melakukan migrasi sirkuler. Tanda negatif pada koefisien berarti bahwa semakin besar pendapatan yang diterima oleh pekerja maka akan menurunkan minat pekerja tersebut untuk tetap melakukan migrasi sirkuler dengan kata lain dengan pendapatan yang semakin besar, pekerja akan cenderung berniat untuk menetap di Kota Mataram, hal ini terjadi karena dengan pendapatan yang besar maka kemampuan pekerja untuk menetap di Kota Mataram, semakin besar dikarenakan mampu untuk membiayai hidup dan juga untuk menyewa maupun membeli tempat tinggal di Kota Mataram. Sebaliknya semakin kecil pendapatan maka akan meningkatkan niat pekerja untuk tetap melakukan migrasi sirkuler dan menurunkan niat untuk menetap di Kota Mataram.

Nilai exp ( $\beta$ ) sebesar 0,219 menunjukkan bahwa semakin meningkat pendapatan pekerja di Kota Mataram sebesar Rp 1 maka akan menurunkan peluang atau kemungkinan untuk tetap melakukan migrasi sirkuler sebesar 0,22 kali atau $22 \%$.

Hal ini sejalan dengan penelitian terdahulu bahwa variabel pendapatan berpengaruh signifikan terhadap minat pekerja melakukan migrasi sirkuler ke Kota Mataram, sesuai dengan teori Ravenstein yang menjelaskan bahwa faktor paling dominan yang mempengaruhi seseorang untuk bermigrasi adalah sulitnya memperoleh pendapatan yang lebih baik di daerah asal dan kemungkinan untuk mendapatkan pendapatan yang lebih baik di daerah tujuan. Sama halnya dengan teori Todaro yang mengatakan bahwa motif ekonomi merupakan pendorong utama seseorang melakukan migrasi.

Hasil penelitian ini mendukung atau memperkuat hasil penelitiaan Anggraini, 2016 yang berjudul pengaruh kondisi individu terhadap keputusan migrasi sirkuler ke Kota Semarang yang menunjukkan hasil penelitian bahwa pendapatan berpengaruh negatif dan signifikan. 
2. Variabel Lama Bekerja Pekerja Di Daerah Tujuan

Nilai koefisien $(\beta)$ sebesar $-0,296$ dan nilai signifikan 0,023 yang artinya bahwa lama bekerja pekerja berpengaruh secara negatif dan signifikan terhadap minat pekerja melakukan migrasi sirkuler. Tanda negatif pada koefisien berarti bahwa semakin lama pekerja bekerja di Kota Mataram maka akan menurunkan minat pekerja tersebut untuk tetap melakukan migrasi sirkuler, melainkan pekerja akan cenderung untuk berniat menetap di Kota Mataram, hal ini dapat dipengaruhi oleh adanya faktor kenyamanan bekerja di Kota Mataram, pekerja yang sudah lama bekerja di daerah tujuan maka akan memiliki jalinan interaksi sosial yang erat di lingkungan tempat kerjanya sehingga memunculkan niat untuk menetap di Kota Mataram. Sebaliknya semakin singkat lama bekerja pekerja cenderung akan meningkatkan minat pekerja untuk tetap melakukan migrasi sirkuler.

Nilai exp ( $\beta$ ) 0,744 berarti bahwa setiap lama bekerja pekerja di Kota Mataram meningkat sebesar 1 tahun maka akan menurunkan peluang atau kemungkinan pekerja tetap melakukan migrasi sirkuler sebesar 0,74 kali atau $74 \%$.

Berkaitan dengan pernyataan Mantra bahwa setelah beberapa lama bekerja di daerah tujuan, seseorang akan cenderung memilih tempat di dekat dengan daerah di mana ia bekerja, dengan kata lain bahwa memilih untuk menetap di daerah tujuan.

Hasil ini mendukung atau memperkuat hasil penelitian yang dilakukan Sanis, 2010 yang menyatakan bahwa variabel lama migrasi berpengaruh negatif dan signifikan.

\section{Variabel Umur Pekerja}

Nilai koefisien $(\beta)$ sebesar 0,163 dan nilai signifikan 0,121 yang artinya bahwa umur pekerja tidak berpengaruh secara signifikan terhadap minat untuk melakukan migrasi sirkuler, baik untuk tetap melakukan migrasi sirkuler ataupun berniat untuk menetap di Kota Mataram. Hal ini dapat terjadi dikarenakan karakteristik responden pada penelitian ini memiliki umur produktif untuk bekerja, selama pekerja tersebut masih mampu untuk bekerja maka ia akan tetap bekerja, baik untuk melakukan migrasi sirkuler maupun tidak, sehingga variabel umur dapat tidak berpengaruh secara signifikan pada penelitian ini.

Hasil penelitian ini mendukung atau memperkuat hasil penelitian dari Anggraini, 2016 yang berjudul pengaruh kondisi individu terhadap keputusan migrasi sirkuler ke Kota Semarang yang menunjukkan hasil penelitian bahwa umur tidak berpengaruh signifikan.

4. Variabel Jarak Daerah Asal Ke Daerah Tujuan Pekerja

Nilai koefisien $(\beta)$ sebesar $-0,091$ dan nilai signifikan 0,005 artinya bahwa jarak berpengaruh negatif dan signifikan terhadap minat pekerja melakukan migrasi sirkuler. Tanda negatif menunjukkan bahwa semakin jauh jarak daerah asal ke Kota Mataram akan menurunkan minat pekerja untuk tetap melakukan migrasi sirkuler, dengan kata lain pekerja cenderung berniat untuk menetap di daerah tujuan karena mempertimbangkan efisiensi biaya, waktu dan tenaga. Sebaliknya semakin dekat jarak daerah asal ke Kota Mataram akan meningkatkan minat pekerja untuk tetap melakukan migrasi sirkuler ke Kota Mataram.

Nilai exp ( $\beta$ ) sebesar 0,913 artinya bahwa semakin jauh jarak antara daerah asal ke Kota Mataram akan menurunkan peluang atau kemungkinan pekerja untuk tetap melakukan migrasi sirkuler sebesar 0,91 kali atau $91 \%$.

Hasil penelitian ini sejalan dengan teori yang diungkapkan oleh Ravenstein, jarak merupakan pertimbangan yang dominan dan utama untuk menentukan minat migrasi seseorang khususnya migrasi yang sifatnya ulang - alik karena mempertimbangkan efisiensi biaya, waktu dan tenaga yang tersedia.

Hasil penelitian ini juga sejalan hasil penelitian yang dilakukan oleh Erlando, 2014 yang berjudul analisis terhadap migran sirkuler di Kota Surabaya yang menunjukkan bahwa variabel jarak berpengaruh negatif dan signifikan.

5. Variabel Tingkat Pendidikan Pekerja

Nilai koefisien sebesar $(\beta)-0,989$ dan nilai signifikan 0,022 artinya bahwa tingkat pendidikan berpengaruh negatif dan signifikan terhadap minat pekerja melakukan migrasi sirkuler ke Kota Mataram. Tanda negatif pada koefisien menunjukkan bahwa semakin tinggi tingkat pendidikan pekerja maka akan menurunkan minat pekerja untuk tetap melakukan migrasi sirkuler, melainkan cenderung berniat untuk menetap di daerah tujuan karena dengan semakin tingginya tingkat pendidikan maka akan semakin besar pula kesempatan untuk dapat bekerja pada sektor modern, pada penelitian ini responden yang melakukan migrasi sirkuler ke Kota Mataram sebagian besar bekerja pada sektor formal. Sebaliknya semakin 
rendahnya tingkat pendidikan pekerja maka akan cenderung tetap melakukan migrasi sirkuler ke Kota Mataram.

Nilai exp ( $\beta$ ) sebesar 0,372 artinya bahwa semakin tinggi tingkat pendidikan pekerja maka akan menurunkan peluang atau kemungkinan minat pekerja untuk tetap melakukan migrasi sirkuler ke Kota Mataram sebesar 0,37 kali atau $37 \%$.

Hasil penelitian ini sejalan dengan penelitian terdahulu yang menyatakan bahwa variabel tingkat pendidikan berpengaruh signifikan terhadap minat pekerja melakukan migrasi sirkuler ke Kota Mataram.

6. Variabel Status Perkawinan Pekerja

Nilai koefisien $(\beta)$ sebesar $-1,051$ dan nilai signifikan 0,216 artinya bahwa status perkawinan tidak berpengaruh signifikan terhadap minat pekerja untuk melakukan migrasi sirkuler baik tetap melakukan migrasi sirkuler maupun berniat untuk menetap di Kota Mataram. Perbedaan status perkawinan responden tidak mempengaruhi minat untuk melakukan migrasi sirkuler.

Hasil penelitian ini mendukung hasil penelitian dari Anggraini, 2016 yang berjudul pengaruh kondisi individu terhadap keputusan migrasi sirkuler ke Kota Semarang yang menunjukkan hasil penelitian bahwa status perkawinan tidak berpengaruh signifikan terhadap minat seseorang untuk melakukan migrasi sirkuler.

\section{SIMPULAN DAN SARAN}

\section{Simpulan} berikut :

Berdasarkan hasil analisis data dan pembahasan hasil penelitian maka diperoleh kesimpulan sebagai

1. Dari 80 orang responden yang melakukan migrasi sirkuler ke Kota Mataram untuk bekerja, 55\% dari jumlah responden tersebut berminat untuk tetap melakukan migrasi sirkuler sedangkan $45 \%$ responden berniat untuk menetap di Kota Mataram. Berarti sebagian besar responden berminat untuk tetap melakukan migrasi sirkuler.

2. Berdasarkan hasil regresi binary logit diperoleh hasil bahwa variabel pendapatan, lama bekerja, umur, jarak, tingkat pendidikan dan status perkawinan secara serentak dapat menjelaskan sekitar $63,70 \%$ minat pekerja melakukan migrasi sirkuler ke Kota Mataram.

3. Secara parsial, variabel pendapatan, lama bekerja, jarak dan tingkat pendidikan berpengaruh signifikan terhadap minat pekerja melakukan migrasi sirkuler ke Kota Mataram

\section{Saran}

1. Pemerintah sebaiknya lebih meningkatkan pemerataan pembangunan diseluruh kabupaten/kota di Provinsi Nusa Tenggara Barat sehingga kegiatan mobilitas penduduk dapat ditekan.

2. Pemerintah lebih peduli pada penyediaan lapangan kerja, terutama di daerah pedesaan agar tenaga kerja di desa tidak perlu lagi bermigrasi untuk mencari pekerjaan. Dengan mengadakan modernisasi sektor pertanian yang merupakan sektor utama daerah pedesaan guna untuk meningkatkan produksi dan produktivitas hasil panen dengan harapan membuka kesempatan kerja untuk tujuan kesejahteraan penduduk. 


\section{DAFTAR PUSTAKA}

Abidin, Zainal. 2013. Analisis Keputusan Tenaga Kerja Melakukan Migrasi Komutasi Di Kecamatan Wuluhan Kabupaten Jember. Skripsi FEB Universitas (tidak dipublikasikan), Jember

Anggraini, Hastu Rahma. 2016. Pengaruh Kondisi Individu Terhadap Keputusan Migrasi Sirkuler ke Kota Semarang. Jurnal FE Universitas Negeri Semarang

Arsyad, Lincolin. 2009. Ekonomi Pembangunan. UPP AMP YKPN Yogyakarta

Badan Pusat Statistik Kota Mataram : PDRB Kota Mataram Atas Harga Konstan 2010 Tahun 2011 - 2017. Kota Mataram

Erlando, Angga. 2014. Analisis Terhadap Migran Sirkuler Di Kota Surabaya. Skripsi FEB Universitas Brawijaya : Malang

Ghozali, Imam. 2012. Aplikasi Analisis Multivariate Dengan Program SPSS.Yogyakarta : Universitas Diponegoro

Hadi, Sutrisno. 2015. Metodologi Riset . Pustaka Pelajar Yogyakarta

Junaidi. 2007. Mobilitas Penduduk Dan Remitan. Fakultas Ekonomi Universitas Jambi : Jambi

Mantra, Ida Bagoes. 2015. Demografi Umum. Pustaka Pelajar : Yogyakarta

Mujinto, Annugrah. 2013. Analisis Faktor - faktor Yang Mendorong Seseorang Untuk Melakukan Migrasi Ulang - alik (Studi Kasus Pada Migran Kota Malang Yang Melakukan Migrasi Ulang - Alik Ke Surabaya Dengan Menggunakan Transportasi Bus). Skripsi FEB Unversitas Brawijaya : Malang

Nuraini, Atik. 2006. Analisis Faktor - Faktor Yang Mempengaruhi Minat Migrasi Sirkuler Menginap/Mondok (Studi Kasus Kabupaten Boyolali). Skripsi S1 (tidak dipublikasikan) FE UNDIP : Semarang

Pangaribuan, Kaisar Hasudungan dan Herniwati Retno Handayani. 2013. Analisis Pengaruh Pendapatan, Pendidikan, Pekerjaan Daerah Asal, Jumlah Tanggungan, dan Status Perkawinan Terhadap Keputusan Migrasi Sirkuler Ke Kota Semarang (Studi Kasus : Kecamatan Tembalang dan Pedurungan). Jurnal FEB Universitas Diponegoro : Semarang (Jurnal dipublikasikan)

Pramesti, Getut. 2013. Smart Olah Data Penelitian. PT Elek Media Komputindo Jakarta

Rozy Munir. 1981. Dasar - Dasar Demografi. Jakarta : Lembaga Demografi Fakultas Ekonomi Universitas Diponegoro.

Rustariyuni, Surya Dewi. 2012. Faktor - faktor Yang Mempengaruhi Minat Migran Melakukan Mobilitas Non Permanen Ke Kota Denpasar. Jurnal FEB Universitas Udayana : Bali

Said, Rusli. 1996. Pengantar Ilmu Kependudukan. LP3ES Jakarta

Sanis, Putu Ayu. 2010. Analisis Pengaruh Upah, Lama Migrasi, Umur, dan Tingkat Pendidikan Terhadap Minat Migrasi Penduduk Salatiga Ke Kota Semarang. Skripsi S1 FE Diponegoro : Semarang

Sujarweni, V Wiratna. 2018. Metodologi Penelitian Bisnis dan Ekonomi Pendekatan Kuantitatif. : Pustaka Baru Press Yogyakarta

Sugiyono. 2012. Metode Penelitian Kuantitatif Kualitatif dan R\&D. Alfabeta Bandung

Todaro, Michael P. 1998. Pembangunan Ekonomi Di Dunia Ketiga. Erlangga ,Jakarta

Villantina, Dina. 2008. Analisis Faktor - faktor yang Mempengaruhi Minat Migrasi ke Kecamatan Pedurungan. Skripsi S1 FE UNDIP : Semarang

Wahyuni, Ida dkk. 2016. Faktor - faktor yang Mempengaruhi Minat Migrasi Sirkuler Penduduk Kecamatan Negara Kabupaten Jembrana. Jurnal Universitas Jember : Jember

Yeremias, T. Keban. 1994. Studi Niat Bermigrasi Di Tiga Kota: Determinan dan Intervensi Kebijakan. Jurnal Prisma

Abdurrahman :Teori Migrasi: http://rahmanp106.blogspot.com/2007/06/teori-migrasi.html?m=1 (diakses tanggal 2 November 2018)

Anonim :Jenis - jenis Migrasi Permanen dan Non permanen: https://ipssmp123.blogspot.com/2014/11/sebutkan-apa-saja-jenis-jenis-migrasi.html (diakses 10 Januari 2019)

Sekaran, Uma. 2017. Metode Penelitian Untuk Bisnis. Salemba Empat Jakarta 